\title{
International Journal of Aquatic Research and Education
}

Volume 6 | Number 2

Article 1

$5-1-2012$

\section{In This Issue...}

Stephen J. Langendorfer

Bowling Green State University, slangen@bgsu.edu

Follow this and additional works at: https://scholarworks.bgsu.edu/ijare

How does access to this work benefit you? Let us know!

\section{Recommended Citation}

Langendorfer, Stephen J. (2012) "In This Issue...," International Journal of Aquatic Research and Education: Vol. 6: No. 2, Article 1.

DOI: https://doi.org/10.25035/ijare.06.02.01

Available at: https://scholarworks.bgsu.edu/ijare/vol6/iss2/1

This Editorial is brought to you for free and open access by the Journals at ScholarWorks@BGSU. It has been accepted for inclusion in International Journal of Aquatic Research and Education by an authorized editor of ScholarWorks@BGSU. 


\section{EDITORIALS}

International Journal of Aquatic Research and Education, 2012, 6, 101-104

(C) 2012 Human Kinetics, Inc.

\section{In This Issue . . .}

\section{Reminder: International Aquatic History Symposium and Film Festival}

As I mentioned in the February issue, the International Swimming Hall of Fame is hosting the first ever International Aquatic History Symposium and Film Festival (IAHSFF) in Ft. Lauderdale, FL on May 2-5, 2012. If you are reading this before May 1, 2012 and are interested in attending the Symposium please refer to the IAHSFF's website, http://iahsff.com/. The Registration for the Symposium admits you to the keynote speakers, viewing posters and presentations, the film series, book signings, and an ISHOF Museum tour.

\section{Update on an Impact Factor for IJARE}

I was disappointed to learn recently that the Institute for Scientific Information (ISI), a part of Thomson Reuters Corporation, a business data provider, decided not to include the International Journal of Aquatic Research and Education within the Thomson Reuters Journal Citation Reports (JCR), which would have allowed us to obtain an impact factor (IF). Perhaps the most disappointing aspect of their decision was the lack of any feedback about why they chose not to include IJARE within JCR. Without that information, we have no idea about how to proceed to remediate any perceived problems. Is it because we are a relatively new journal? Is it because we are a niche journal (how many other aquatic journals can you identify)? Is it because IJARE articles are not already widely cited in the JCR or the ISI Web of Science database? I hope you can appreciate how frustrating not receiving feedback is!

I did discover how the ISI impact factor is purportedly calculated. The calculation is much simpler than I anticipated: It is the simple ratio of the total number of citations of IJARE articles appearing in all the JCR publications to the total number of "citable" papers (e.g., does not include editorials or letters to the editor) that were published in IJARE for a particular time period. The IF normally is time limited to a three-year period, and a five-year average IF is reported as well. For a review of a few criticisms of IF, I refer you to my editorial in the 5(4) issue entitled "Scholarly peer review versus impact factors" and to a letter to the editor from Stathis Avramidis in the previous issue, 6(1). You also can find a number of citations about IF using an online search.

I am assured that Human Kinetics will continue to apply for inclusion in the JCR (that allows calculation of an impact factor) until we are accepted. As soon as we are permitted, HK again will apply to PubMed and Medline for inclusion in their indices to enable wider dissemination and access to our published papers. I promise to keep you updated on any new information as it becomes available. 


\section{In This Issue}

This second issue of the sixth volume of the International Journal of Aquatic Research and Education may be one of the more interesting and unique in our Journal's history. I believe each of the articles published here has the potential to become a classic publication and to be highly cited in the aquatic literature due to their topics and high quality. It has been really exciting to pull this issue together as I realized the manuscripts that were ready for publication together!

This issue begins with another of my editorials entitled, "Instructional Aids: To Use or Not to Use?" Over the years I have had many discussions with aquatic colleagues and parents regarding the use of what I call "instructional aids" that range from "floaties," "bubbles," and noodles to fins, pull buoys, goggles, and even water toys like rubber ducks. Recently, the issue of the efficacy and appropriateness of certain instructional aids arose again. In fact, I recommend Per-Ludvik Kjendlie's research paper in this issue that relates to this very topic. The editorial offers me an opportunity to muse a bit about how the concepts of a developmental perspective and developmentally appropriate practices (DAP) may provide some insight into addressing the controversy. As always, I am eager to hear other opinions on the topic, both agreeing and disagreeing. Send those letters to the editor!

\section{Research Articles}

We publish five excellent research articles in this unique issue, several of which you will discover are closely connected by common authors and topics! The first paper, "Swim Instructor Beliefs about Toddler and Pre-School Water Safety Education," was authored by a number of our colleagues from "down under." Jenny Blitvich, Lauren Petrass, G. McElroy, and Teresa Stanley from the University of Ballarat along with Kevin Moran from the University of Auckland in New Zealand conducted this fascinating survey study to identify the goals and messages being conveyed by swimming instructors, particularly those with an "extension" to teach toddlers and pre-schoolers. I think you will want to read this paper closely to discover several disconcerting misunderstandings that many instructors seem to hold about the purpose and outcomes of pre-school swim lessons.

I have written about the exciting international Can You Swim? study on drowning prevention in previous editorials (c.f., my editorial, "Considering drowning, drowning prevention, and learning to swim," pp. 236-242, in the 2011 August issue). The next two research articles in the current issue represent some of the first publications emanating from this world-wide collaborative research effort. I am particularly pleased that both articles appear in this same issue so that readers can get a better understanding of some of the questions being addressed regarding what it means to be competent in swimming and how those skills or competencies may impact drowning prevention efforts.

The authors of the second article, Kevin Moran (New Zealand), Robert KeigStallman, and Per-Ludvik Kjendlie (Norway), Jenny Blitvich and Lauren Petrass (Australia), and Toshiaki Goya (Japan) pooled their four collective data sets and offer you "Can You Swim? An Exploration of Measuring Real and Perceived Water Competency." The effort to pool data collected in four different countries 
and cultures, analyze it, and then offer generalizations struck me as monumental and mind-boggling. Readers interested in perceived and actual water competence definitely will want to explore this article, probably reading it several times to absorb the important messages.

By the time you reach the third article, "Can You Swim? Comparison between Self-Report and Actual Swimming Competency Among Young Adults in Ballarat, Australia," authored by Lauren Petrass, Jenny Blitvich, G. McElroy, and Jack Harvey from the University of Ballarat in Australia, and Kevin Moran from the University of Auckland in New Zealand, I suspect that readers ought to realize how busy some of our illustrious colleagues have been over the past year or so. Obviously, this third article explores the Australian data set from the first phase of the Can You Swim? project in greater depth, arriving at some similar as well as different conclusions about perceived and actual swimming competency that you will want to compare with the previous article.

As if the connections among the authors of this issue already were not apparent, you will discover that "Movement Patterns in Free Water Play After Swimming Teaching With Flotation Aids" was authored by Per-Ludvik Kjendlie and Marcel Mendritzki, both from the Norwegian School of Sport Sciences, Department of Physical Performance, in Oslo, Norway. Per-Ludvik obviously was involved in the Norwegian data set related to phase 1 of Can You Swim? As I mentioned in the introduction of my editorial in this issue, Per-Ludvik and Marcel addressed a question about the degree to which an instructional flotation vest may have limited children's learning and free play choices. I found it to be a critical study to add an evidence basis to an issue that is dominated too much by opinion.

The final research article comes from another familiar research team who regular readers should immediately recognize. Andrew Cornett (currently at Eastern Michigan University), along with his former colleagues from Indiana University's Councilman Center for Aquatic Research, Josh White, Brian Wright, and Joel Stager, have employed a rather different methodology from their previous studies on swimming starts in producing, "Teaching Competitive Racing Starts: Practices and Opinions of Professional Swim Coaches." Showing their wide ranging talents beyond their earlier biomechanical measures, this research team validated and implemented a nationwide online survey of registered USA Swimming coaches to investigate how racing starts are taught by coaches and discover whether they could recommend a sound and safe teaching progression for swimming entries.

\section{Original Educational Article}

We conclude this issue with a comprehensive and interesting educational review paper contributed by Ellen Broach, a distinguished member of IJARE's Editorial Board from the University of South Alabama, and her co-author, Alexis McKenney, from Florida International University. Entitled "Social Fun and Enjoyment: Viable Outcomes in Aquatics for Individuals with Physical Disabilities," the paper explores a diverse literature related to the affective domain of aquatic activities and programs for individuals with disabilities. More broadly, Ellen and Alexis explore definitions and information regarding enjoyment and social fun as they relate them to ideas such as Csikszentmihalyi's concept of "flow" and how they can be exploited 
International Journal of Aquatic Research and Education, Vol. 6, No. 2 [2012], Art. 1 104 Langendorfer

to improve the experiences of and adherence in aquatic programs for persons who are differently-abled. The depth and breadth of related information they explore is impressive indeed. I hope you will agree.

Until our next issue in August, as always, good reading and safe swimming.

Steve Langendorfer, Editor International Journal of Aquatic Research and Education 